\title{
Fulminant type 1 diabetes in Korea: high prevalence among patients with adult-onset type 1 diabetes
}

\author{
Y. M. Cho • J. T. Kim • K. S. Ko • B. K. Koo • \\ S. W. Yang $\cdot$ M. H. Park $\cdot$ H. K. Lee $\cdot$ K. S. Park
}

Received: 9 July 2007 / Accepted: 3 August 2007 / Published online: 28 August 2007

(C) Springer-Verlag 2007

\begin{abstract}
Aims/hypothesis The aim of this study was to investigate the prevalence of fulminant type 1 diabetes and the clinical characteristics of the disease among newly diagnosed Korean patients.

Methods Using data retrieved from the Seoul National University Hospital database, we identified all patients newly diagnosed with type 1 diabetes from 1 January 1999 to 31 July 2006. Information on clinical manifestations and laboratory data, including the presence of islet autoantibodies detected at diagnosis, were obtained by reviewing medical records.

Results We identified 99 patients newly diagnosed with type 1 diabetes. Seven patients (7.1\%) fulfilled the criteria for fulminant type 1 diabetes. Among the patients aged $\geq 18$ years at onset, $30.4 \%$ had fulminant type 1 diabetes.
\end{abstract}

Y. M. Cho and J. T. Kim contributed equally to this work.

Y. M. Cho · J. T. Kim • B. K. Koo • H. K. Lee $\cdot$ K. S. Park $(\bowtie)$

Department of Internal Medicine,

Seoul National University College of Medicine,

28 Yongon-dong, Chongno-gu,

Seoul 110-744, South Korea

e-mail: kspark@snu.ac.kr

K. S. Ko

Department of Internal Medicine,

Inje University College of Medicine,

Seoul, South Korea

S. W. Yang

Department of Paediatrics,

Seoul National University College of Medicine,

Seoul, South Korea

M. H. Park

Department of Laboratory Medicine,

Seoul National University College of Medicine,

Seoul, South Korea
Patients with this diabetes subtype tested negative for islet autoantibodies, had a higher age of onset (median 28 vs 10 years, $p<0.001$ ) and a markedly shorter duration from onset of hyperglycaemic symptoms to first hospital visit (median 3 vs 30 days, $p<0.001$ ) than patients with nonfulminant type 1 diabetes, and showed trends of increased serum aspartate aminotransferase and amylase levels and a decreased glucagon-stimulated serum C-peptide response. Conclusions/interpretation In Korea, the prevalence of fulminant type 1 diabetes was $7.1 \%$ among all patients newly diagnosed with type 1 diabetes and $30.4 \%$ among patients with adult-onset diabetes. The clinical and metabolic characteristics of the patients with fulminant type 1 diabetes were similar to those reported in Japanese studies.

Keywords Epidemiology · Fulminant type 1 diabetes mellitus · Korea

$\begin{array}{ll}\text { Abbreviations } \\ \text { ALT } & \text { alanine aminotransferase } \\ \text { AST } & \text { aspartate aminotransferase } \\ \text { IA-2Ab } & \text { insulinoma-associated protein } 2 \text { antibodies } \\ \text { ICA } & \text { islet cell antibodies } \\ \text { IAA } & \text { insulin autoantibodies } \\ \text { GADAb } & \text { GAD antibodies }\end{array}$

\section{Introduction}

Fulminant type 1 diabetes was initially reported as a distinct subtype of type 1 diabetes [1], defined by a remarkably abrupt onset and diabetic ketoacidosis or ketosis at initial presentation. Patients generally have a low $\mathrm{HbA}_{1 \mathrm{c}}$ level $(<8.5 \%)$ relative to the initial marked hyperglycaemia; test 
negative for islet autoantibodies such as islet cell antibodies (ICA), GAD antibodies (GADAb), insulin autoantibodies (IAA), and insulinoma-associated protein 2 antibodies (IA$2 \mathrm{Ab})$; have virtually no C-peptide secretion $(<10 \mu \mathrm{g}$ /day in urine); and have elevated serum pancreatic enzyme levels. In Japan, the prevalence of fulminant type 1 diabetes among patients with acute-onset type 1 diabetes has been reported as $19.4 \%$ [2]. However, it may not occur, else have a very low prevalence, in other ethnic groups, especially in Europids [3-5]. Although a few cases of fulminant type 1 diabetes have been reported in Korea [6,7], information on the prevalence and clinical characteristics of fulminant type 1 diabetes in countries other than Japan is scarce. Based on this, we investigated the prevalence and clinical characteristics of fulminant type 1 diabetes among Korean patients newly diagnosed with type 1 diabetes.

\section{Methods}

Patients By retrieving data from the Seoul National University Hospital database, we identified all patients newly diagnosed with type 1 diabetes from 1 January 1999 to 31 July 2006. The Institutional Review Board of the Clinical Research Institute in Seoul National University Hospital approved our study protocol. Clinical characteristics, such as age at onset, sex, BMI, blood pressure, duration of hyperglycaemic symptoms prior to diagnosis, and family history of diabetes, were obtained by reviewing medical records. Laboratory data, including plasma glucose and $\mathrm{HbAlc}$ levels, serum concentrations of electrolytes, bicarbonate, aspartate aminotransferase (AST), alanine aminotransferase (ALT), total cholesterol, triacylglycerol, HDL-cholesterol, amylase, lipase, and fasting C-peptide, $24 \mathrm{~h}$ urinary C-peptide excretion, glucagon- or mealstimulated C-peptides, arterial blood $\mathrm{pH}$, and anion gap at initial presentation of type 1 diabetes, were also obtained from the medical records. HbAlc levels had been measured by affinity chromatography using the Bio-Rad Variant II system (Bio-Rad Laboratories, Hercules, CA, USA).

We excluded patients diagnosed with latent autoimmune diabetes in adults. Fulminant type 1 diabetes was defined by the following criteria [8]: (1) the presence of increased urinary and/or serum ketone bodies at first visit, shortly after (approximately 7 days) the onset of hyperglycaemic symptoms; (2) a plasma glucose level of $\geq 16 \mathrm{mmol} / \mathrm{l}$ and an $\mathrm{HbA1c}$ level of $<8.5 \%$ at first visit; and (3) a urinary Cpeptide excretion level of $<10 \mu \mathrm{g} /$ day or a fasting C-peptide level of $<0.1 \mathrm{nmol} / 1$ or a serum C-peptide level of $<0.2 \mathrm{nmol} / 1$ after glucagon injection or glucose loading.

Insulin requirements as unit per kilogram per day and $\mathrm{HbA}_{1 \mathrm{c}}$ levels up to 1 year after initial diagnosis were reviewed to examine the presence of a 'honeymoon period', which was arbitrarily defined as a period with insulin requirements of $<0.5 \mathrm{U} \mathrm{kg}^{-1}$ day $^{-1}$ [9].

Autoantibodies The presence of islet autoantibodies (GADAb, IA-2Ab and IAA) was determined by reviewing the medical records. Three patients were tested for all three islet autoantibodies, 46 patients were tested for two of these autoantibodies, and the remaining 50 patients were tested only for GADAb. GADAb was measured by a radioimmunoassay (RSR, Cardiff, UK), IAA was measured by a radioimmunoassay (BioSource, Nivelles, Belgium), and IA-2Ab was measured by radioimmunoprecipitation assays using radiolabelled recombinant ICA512bdc as antigens, as described previously [10].

HLA genotypes With written informed consent, HLA genotyping was performed using DNA samples extracted from peripheral blood cells. Sequencing reactions were performed using the AlleleSEQR HLA Sequencing Kit (Atria Genetics, South San Francisco, CA, USA) and then analysed using an ABI 3100 Genetic Analyzer (Applied Biosystems, Foster City, CA, USA) and Assign-SBT software (Conexio Genomics, Perth, WA, Australia).

Statistical analysis All continuous variables with a normal distribution are expressed as means $\pm \mathrm{SD}$, while those with a skewed distribution are expressed as medians (range). The $\chi^{2}$ and Mann-Whitney $U$ tests were performed using SPSS software (SPSS, Chicago, IL, USA). A $p$ value of $<0.05$ was considered statistically significant.

\section{Results}

We identified 99 patients newly diagnosed with type 1 diabetes from January 1999 through July 2006 using the available data regarding clinical manifestations and laboratory findings, including those of $\mathrm{HbA}_{1 \mathrm{c}}$ levels and of the presence of islet autoantibodies detected at initial presentation. Among these patients, 68 were positive for a minimum of one type of islet autoantibody, i.e. GADAb, IAA or IA-2Ab.

The criteria for fulminant type 1 diabetes were fulfilled by seven of the 99 patients (7.1\%). Of these seven patients, none were positive for islet autoantibodies. Among the patients with adult-onset type 1 diabetes (age at onset $\geq 18$ years), $30.4 \%$ had fulminant type 1 diabetes (seven out of 23 ). No patient with an age onset of $<18$ years was this diabetes subtype. Seven out of $55(12.7 \%)$ patients who presented with diabetic ketoacidosis (DKA) or ketosis (elevation of serum or urinary ketone levels) had fulminant type 1 diabetes.

The clinical characteristics of the patients are shown in Table 1. The age at onset was higher for patients with 
Table 1 Clinical characteristics of fulminant type 1 diabetes compared to autoimmune or antibody-negative type 1 diabetes

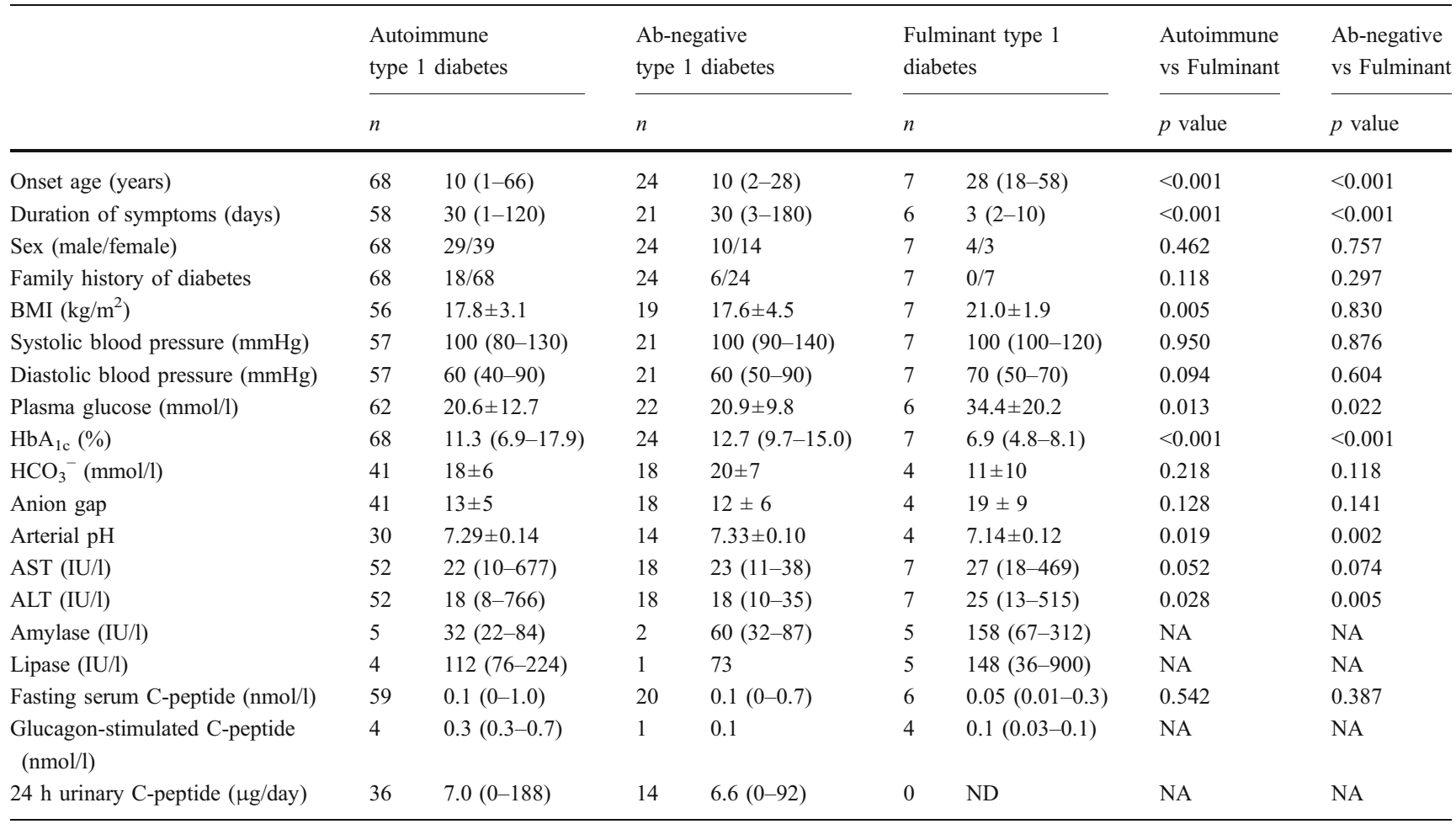

Data were obtained at the time of diagnosis and are presented as means $\pm \mathrm{SD}$ or median (range) or $n$ (positive/negative)

$N D$ Not determined, $N A$ not applicable

fulminant type 1 diabetes than for those with autoimmune or antibody-negative type 1 diabetes $(p<0.001)$. The mean BMI of patients with the fulminant subtype was higher than that of the patients with autoimmune type 1 diabetes but was similar to that of 14 age- and sex-matched patients with autoimmune type 1 diabetes (data not shown). Patients with fulminant type 1 diabetes tended to have higher insulin requirements than those with non-fulminant type 1 diabetes during the first 6 months after diagnosis, and fair glycaemic control was maintained in both groups (data not shown). Interestingly, 30 of the 68 patients with autoimmune type 1 diabetes had a 'honeymoon period', arbitrarily defined as a period with insulin requirements of less than $0.5 \mathrm{U} \mathrm{kg}^{-1} \mathrm{day}^{-1}$ [9], whereas none of the fulminant type 1 diabetes patients did.

The characteristics of the individual patients with fulminant type 1 diabetes are shown in Table 2. All exhibited marked hyperglycaemia and DKA or ketosis at first visit. Three patients showed flu-like symptoms immediately prior to diagnosis. Gastrointestinal symptoms, such as abdominal pain, nausea and vomiting, were present in six patients (all except patient no. 7). Elevated levels of exocrine pancreatic enzymes, such as amylase and lipase, were observed in five patients. Four of them underwent abdominal imaging tests (computed tomography or sonog-

Table 2 Characteristics of individual patients with fulminant type 1 diabetes

\begin{tabular}{|c|c|c|c|c|c|c|c|c|c|c|c|c|}
\hline $\begin{array}{l}\text { Patient } \\
\text { number }\end{array}$ & Sex/age & $\begin{array}{l}\text { BMI } \\
\left(\mathrm{kg} / \mathrm{m}^{2}\right)\end{array}$ & $\begin{array}{l}\text { Duration of } \\
\text { symptoms } \\
\text { (days) }\end{array}$ & $\begin{array}{l}\text { Flu-like } \\
\text { symptoms }\end{array}$ & $\begin{array}{l}\text { Arterial } \\
\mathrm{pH}\end{array}$ & $\begin{array}{l}\text { Urinary } \\
\text { ketone }\end{array}$ & $\begin{array}{l}\text { Plasma } \\
\text { glucose } \\
(\mathrm{mmol} / \mathrm{l})\end{array}$ & $\begin{array}{l}\mathrm{HbA}_{1 \mathrm{c}} \\
(\%)\end{array}$ & GADAb & $\begin{array}{l}\text { Fasting serum } \\
\text { C-peptide } \\
(\mathrm{nmol} / \mathrm{l})\end{array}$ & $\begin{array}{l}\text { Amylase } \\
(60-180 \mathrm{IU} / 1)\end{array}$ & $\begin{array}{l}\text { Lipase } \\
(22-51 \text { IU/l) }\end{array}$ \\
\hline 1 & $\mathrm{M} / 58$ & 19.9 & 5 & + & 7.30 & + & 29.8 & 6.5 & - & $<0.1$ & 312 & 285 \\
\hline 2 & $\mathrm{~F} / 28$ & 19.0 & 3 & - & 7.29 & + & 25.3 & 5.8 & - & $<0.1$ & 110 & 124 \\
\hline 3 & $\mathrm{~F} / 19$ & 21.0 & 5 & + & 7.01 & + & 27.4 & 7.0 & - & $<0.1$ & ND & ND \\
\hline 4 & $\mathrm{M} / 33$ & 21.0 & 10 & - & ND & + & 22.7 & 8.0 & - & $<0.1$ & 67 & 942 \\
\hline 5 & $\mathrm{~F} / 18$ & 25.0 & 3 & + & 7.11 & + & 30.5 & 4.8 & - & $<0.1$ & 158 & 148 \\
\hline 6 & $\mathrm{M} / 27$ & 20.4 & 3 & - & 7.09 & + & 79.9 & 6.8 & - & $<0.1$ & ND & ND \\
\hline 7 & $\mathrm{~F} / 45$ & 20.4 & 2 & - & 7.10 & + & 25.6 & 8.1 & - & $<0.1$ & 233 & 36 \\
\hline
\end{tabular}

$M$ Male, $F$ female, $N D$ not determined or not available 
raphy) but there was no evidence of pancreatitis. HLA DRDQ genotypes were determined in two patients who were very recently diagnosed with fulminant type 1 diabetes: one was homozygous for $H L A-D R B 1 * 0405-D Q B 1 * 0401$ (patient no. 1) and the other was heterozygous for $H L A$ $D R B 1 * 0405 / * 1202-D Q B 1 * 0301 / * 0401$ (patient no. 2).

\section{Discussion}

In the present study we have shown that fulminant type 1 diabetes is not uncommon and is a discrete subtype of type 1 diabetes in Korea. The prevalence of fulminant type 1 diabetes was $7.1 \%$ among all patients newly diagnosed with type 1 diabetes, and $30.4 \%$ among those with an age at onset of $\geq 18$ years. In this study, no patient with an age at onset of $<18$ years was diagnosed with fulminant type 1 diabetes. These findings confirm that fulminant type 1 diabetes is most likely a disease with adult onset [2].

As the definition of fulminant type 1 diabetes implies, the duration from the onset of hyperglycaemic symptoms to the first hospital visit is very short. At presentation, patients with fulminant type 1 diabetes had very high plasma glucose levels with inappropriately low $\mathrm{HbA}_{1 \mathrm{c}}$ levels. They tested negative for islet autoantibodies. Metabolic derangement was very severe, and increased serum pancreatic enzyme levels were observed in these patients. Interestingly, none of the patients with fulminant type 1 diabetes experienced the 'honeymoon period', which suggests that the beta cells of these patients were almost completely and irreversibly destroyed. All these findings are consistent with those of Japanese studies [1,2]. However, we did not identify a pregnancy-associated case, which was a characteristic finding in Japan [2]. A worldwide collaborative epidemiological study will be of help in further characterisation of fulminant type 1 diabetes and facilitate its effective management.
Acknowledgements This study was supported by a grant from the Korea Health 21 R\&D Project, Ministry of Health and Welfare, Republic of Korea (no. 00-PJ3-PG6-GN07-001).

Duality of interest The authors declare that there is no duality of interest associated with this manuscript.

\section{References}

1. Imagawa A, Hanafusa T, Miyagawa J, Matsuzawa Y (2000) A novel subtype of type 1 diabetes mellitus characterized by a rapid onset and an absence of diabetes-related antibodies. Osaka IDDM Study Group. N Engl J Med 342:301-307

2. Imagawa A, Hanafusa T, Uchigata $Y$ et al (2003) Fulminant type 1 diabetes: a nationwide survey in Japan. Diabetes Care 26:2345-2352

3. Maldonado M, Hampe CS, Gaur LK et al (2003) Ketosis-prone diabetes: dissection of a heterogeneous syndrome using an immunogenetic and beta-cell functional classification, prospective analysis, and clinical outcomes. J Clin Endocrinol Metab 88:5090-5098

4. Pozzilli P, Visalli N, Leslie D (2000) No evidence of rapid onset (Japanese) type I diabetes in Caucasian patients. IMDIAB Group. Diabetologia 43:1332

5. Balasubramanian K, Dabadghao P, Bhatia V et al (2003) High frequency of type 1B (idiopathic) diabetes in North Indian children with recent-onset diabetes. Diabetes Care 26:2697

6. Jung JH, Hahm JR, Kim MA et al (2005) Fulminant autoantibody-negative and type 1A diabetes phenotypes in a Korean HLA identical dizygotic twin. Diabetes Care 28:2330-2331

7. Jung TS, Chung SI, Kim MA et al (2004) A Korean patient with fulminant autoantibody-negative type 1 diabetes. Diabetes Care 27:3023-3024

8. Imagawa A, Hanafusa $T$ (2006) Fulminant type 1 diabetes mellitus. Endocr J 53:577-584

9. Chase HP, MacKenzie TA, Burdick J, et al. (2004) Redefining the clinical remission period in children with type 1 diabetes. Pediatr Diabetes 5:16-19

10. Yu J, Shin CH, Yang SW, Park MH, Eisenbarth GS (2004) Analysis of children with type 1 diabetes in Korea: high prevalence of specific anti-islet autoantibodies, immunogenetic similarities to Western populations with "unique" haplotypes, and lack of discrimination by aspartic acid at position 57 of DQB. Clin Immunol 113:318-325 